\title{
Trabalho docente, PROEJA e currículo integrado: algumas reflexões
}

\author{
Edaguimar Orquizas Viriato* \\ Aparecida Favoreto** \\ Lígia Regina Klein ${ }^{* * *}$
}

\section{Resumo}

$\mathrm{Na}$ infinidade de questôes que perpassam o debate do currículo escolar, em sua vastíssima complexidade, elegemos a questáo do trato do conhecimento no currículo integrado, presente na política educacional voltada para a Educação Profissional, particularmente ao Programa de Integração da Educação Profissional ao Ensino Médio na Modalidade de Educação de Jovens e Adultos (PROEJA). Adotamos como recurso metodológico a pesquisa bibliográfica, que compreendeu o levantamento e a análise de fontes primárias (legislação educacional) e fontes secundárias (teses, dissertaçôes, relatórios de pesquisa, livros e periódicos). Apontamos para a necessidade de se postular um currículo que esteja integrado ao método, o qual, por sua vez, expresse a luta de classes em perspectiva de totalidade, ou seja, que possibilite trabalhar os elementos integradores da vida humana em seu movimento histórico e contraditório. Palavras-chave: Integração Curricular. Conhecimento. Educação Profissional Integrada.

\footnotetext{
Doutora em Educação pela Pontifícia Universidade Católica de São Paulo (PUC/SP). Professora do Curso de Pedagogia e do Mestrado em Educação da Universidade Estadual do Oeste do Paraná (Unioeste).

** Doutora em Educação pela Universidade Federal do Paraná (UFPR).

*** Doutora em Educação pela Pontifícia Universidade Católica de São Paulo (PUC/SP).
} 


\section{Introdução}

Iniciamos o artigo trazendo à memória a música "Cálice", de Chico Buarque e Gilberto Gil (1973): "Pai! Afasta de mim esse cálice; Pai! Afasta de mim esse cálice; Pai! Afasta de mim esse cálice". Com esta referência, queremos compartilhar com os nossos leitores algumas inquietaçóes referentes ao conhecimento no currículo integrado, presente na política educacional voltada para a Educação Profissional, particularmente ao Programa de Integração da Educação Profissional ao Ensino Médio na Modalidade de Educação de Jovens e Adultos (PROEJA).

Para melhor situar a posição a partir da qual enfrentamos a discussão, destacamos que compreendemos o currículo como campo de luta política, em que o conhecimento é entendido como poder, razão pela qual a apropriação do saber universal sistematizado ao longo da história é condição para a emancipação dos excluídos (SAVIANI, 1983). Sob esse ponto de vista, atenta-se para pesquisa do IBGE revelando que o "[...] País tem pior evasão escolar do Mercosul" e possui um "[...] alto índice de abandono: 14,8\% dos adolescentes de 15 a 17 anos estão fora das salas de aula" (PAÍ́s, 2010). No mesmo sentido, verificase que uma considerável parcela social está abandonada à própria sorte. Até quando, José?

Se eu pudesse, dava um toque em meu destino, não seria um peregrino nesse imenso mundo cão. Nem um bom menino que vendeu limão.Trabalhou na feira pra comprar seu pão. Não aprendia as maldades que essa vida tem. Mataria a minha fome sem ter que roubar ninguém. Juro que eu não conhecia a famosa Funabem, onde foi a minha morada desde os tempos de neném. É ruim acordar de madrugada, pra vender bala no trem. Se eu pudesse eu tocava em meu destino. (GUARÁ; FERNANDINHO, 2006).

De diversas formas, músicas, pinturas, filmes, aulas, teses, artigos abordam a nossa realidade societal e nos impóem a questão: "Como beber dessa bebida amarga/tragar a dor e engolir a labuta?” (BUARQUE; GIL, 1973).

O problema social, mesmo não raro tendo sido mal interpretado como infortúnio individual, tem aumentado em proporçáo e complexidade. E, como 
frequentemente acontece, aumentam as exigências feitas aos professores e à escola, enquanto o eu docente é relegado ao silêncio. Trata-se de um silêncio construído pelas contradiçôes impressas nos fatos sociais e pelo peso de um discurso hegemônico, tecido com palavras de sentido dúbio, vago ou mesmo sem sentido. Silêncio que desborda uma prática pedagógica que pretende ser possível tangenciar aquelas contradições da realidade social. É a imersão no imediato perene, no vazio interminável, ciência sem ciência.

Neste cenário, é oportuno lembrar o questionamento de Viriato (2010, p. 772): "Não é possível encher as prateleiras das bibliotecas com monografias, dissertaçóes e teses e a educação continuar com os nossos alunos, filhos de trabalhadores, futuros trabalhadores e trabalhadores passando e passando e passando."

Com efeito, na corrida por publicaçóes, o silêncio tem se alimentado do isolamento de nossa prática docente, embargando a utopia a que nos chama o movimento da história: "Como é difícil acordar calado/se na calada da noite eu me dano/quero lançar um grito desumano/que é uma maneira de ser escutado" (BUARQUE; GIL, 1973). Se ontem era preciso recorrer a metáforas para ser escutado - e os compositores da cançáo driblaram a censura, metaforizando o conteúdo de seu grito -, hoje, parece possível falarmos abertamente sem repressão, sem censura declarada. $\mathrm{O}$ oponente parece não ter motivos para receios. Apesar da miséria, apesar do insucesso da escola pública para a classe trabalhadora, o consenso em torno da naturalização da exploração capitalista, da culpabilização pelo fracasso escolar e/ou outros hegemoniza o pensamento coletivo.

Quanto aos trabalhadores, têm que produzir! E nós, trabalhadores da educação, produzimos... No silêncio. No individualismo exacerbado... No isolamento e no silêncio das nossas aulas, produzimos! Sequer sabemos se somos escutados.

Essa realidade nos transtorna como um grito preso na garganta, e nos anima a pensar as contradiçóes e incoerências a serem enfrentadas no debate sobre o currículo escolar, por um lado, sob o peso do espectro das determinaçôes mercadológicas e todo seu desdobramento competitivo, que atribui a cada professor, à organização e à gestão escolar a culpa pelos problemas da educação; por outro lado, como consequência de diversas atividades desenvolvidas, nas quais temos buscado abordar criticamente alguns elementos que interferem na implementação de uma política educacional, neste caso, o PROEJA, que, 
com todos os limites da sociedade capitalista, possa contribuir para que os trabalhadores transponham os atuais limites que os condenam à privação do conhecimento.

Neste embate, o que ensinar, como ensinar, por que ensinar e para quem ensinar são questóes que perpassam o currículo e, longe de serem neutras, congregam uma luta, como argumenta Silva:

O currículo é lugar, espaço, território. O currículo é relaçẫo de poder. $\mathrm{O}$ currículo é trajetória, viagem, percurso. O currículo é autobiografia, nossa vida, curriculum vitae: no currículo se forja nossa identidade. O currículo é texto, discurso, documento. O currículo é documento de identidade. (SILVA, 1996, p. 150).

A educação, a escola e, no nosso caso, toca especificamente o tema deste artigo, o currículo sempre estiveram em disputa, seja na Educação Básica, seja no Ensino Superior, desde suas origens, em que já se fazia clara a marca da dualidade do ensino, sob os ditames da sociedade capitalista.

Sendo um espaço de luta, o currículo e suas implicaçôes para a educação e a escola nos obrigam um olhar que não permite nenhum resquício de ingenuidade. Assim, na infinidade de questôes que perpassam o debate do currículo escolar, em sua vastíssima complexidade, elegemos a questão do trato do conhecimento no currículo integrado, sob o aspecto da correlaçáo de forças sociais que se estabelecem no discurso educacional.

Para desenvolver o artigo, utilizamos como recurso metodológico a pesquisa bibliográfica, que compreendeu o levantamento e a análise de fontes primárias (legislaçáo educacional) e fontes secundárias (teses, dissertaçóes, relatórios de pesquisa, anais de eventos, livros, revistas, jornais e periódicos).

\section{Educação integrada, currículo integrado, PROEJA}

No Brasil, a discussão sobre educação integral e/ou integrada surge em conjunto com o debate sobre a constituição da escola pública, o qual toma caráter de movimento social com a publicação do "Manifesto dos Pioneiros da Escola Nova" em 1932 (AZVEDO, 2006), em defesa da constituição de um sistema de ensino nacional, laico, gratuito, obrigatório e único. Os signatários do "Manifesto de 1932" defendem que o currículo escolar deve se integrar ao 
seu meio social, fulcrados em uma ideia do "direito biológico do indivíduo" à "educação integral" (AZEVEDO, 2006).

Com base nos princípios teóricos de Dewey (1979) e de Durkheim (1965), o "Manifesto de 1932" firmou-se na luta contra o sistema tradicional de ensino e pela noção de escola como uma instância que poderia integrar o cidadáo brasileiro ao ritmo de desenvolvimento produtivo e democrático das naçôes mais adiantadas. No que se refere à escola tradicional, denunciava sua perspectiva presa a conhecimentos abstratos, em que o aluno apenas repetia formalmente os conteúdos previamente estabelecidos pelo professor. Dessa forma, não estimulava $o$ interesse da criança nem a colocava em contato com a vida.

Para os signatários do "Manifesto", ou seja, os chamados escolanovistas, a escola deveria se organizar como uma sociedade em miniatura, de forma que os alunos entendessem as leis gerais da sociedade, e por elas se dirigissem na busca da soluçáo dos problemas diários. $\mathrm{Na}$ busca de integrar a escola à vida, defendia-se que a repetição de abstraçôes deveria ser substituída pelo aprender a aprender.

Para integrar os indivíduos ao progresso das naçôes mais desenvolvidas, os escolanovistas brasileiros defendiam que a educação escolar não poderia mais ficar restrita a uma classe social abastada, mas deveria estar ao alcance de todos. Desta forma, sem distinção de classe social, a escola permitiria que todos, segundo sua capacidade biológica, se integrassem ao fluxo do progresso. Para os escolanovistas, a escola experimental poderia transformar o homem brasileiro: de um sujeito cheio de crendices, apático e subordinado ao mando local, em um homem mais autônomo, solidário, produtivo e inteligente ${ }^{1}$. Assim, centram-se no ideal de transformar a educação para que transforme indivíduos e, consequentemente, transforme a sociedade.

Nesse ideal, não questionam os fundamentos individualizantes e meritocráticos da sociedade, e a análise recai sobre a educação que forma indivíduos competentes para se adequarem ao desenvolvimento social. Com base em Duarte (2008, p. 2), podemos afirmar que os escolanovistas "[...] acabam sendo neutralizados pela crença na possibilidade de resolução dos problemas sociais sem necessidade de superação radical da atual forma de organização da sociedade, a qual tem como centro dinâmico a lógica do capital”.

Hoje, a discussão sobre a renovação curricular foi fortalecida com a transição do sistema keynesiano/fordista para a chamada "acumulação flexível"2. 
Nesse cenário, divulga-se a necessidade de desenvolver novas competências, de modo que o indivíduo adquira capacidade de raciocínio e de percepção, e se torne mais flexível, autônomo e polivalente. Neste sentido, defende uma formação "[...] mais geral e abstrata, de modo que permita aos indivíduos perceber as novas chances e encontrar novos caminhos" (PAIVA, 1990, p. 43).

No que se refere à Educação Profissional, para atender à suposta necessidade de desenvolver novas competências exigidas pelo mercado, promulga-se o Decreto 2.208/97 (BRASIL, 1997), em que se institui um sistema de formação profissional equivalente. Tal sistema limita-se a estabelecer concomitância ou formação sequencial como únicas alternativas de articulação entre educação geral e profissional e, nesse sentido, aponta a independência da Educação Profissional em relação aos níveis de escolaridade, o que acaba por incorrer no fim da possibilidade de integração entre educação escolar e trabalho. Nesse aspecto, mantém a histórica dualidade entre formação geral e profissional, e a educação profissional limita-se ao interesse do mercado.

O conteúdo curricular, nesta direção, busca atender aos interesses imediatos do indivíduo do capitalismo. Nesse jogo, defende um currículo baseado em uma racionalidade social. Uma visão parcial e utópica, visto que resgata a superioridade da racionalidade democrática, à qual, por direito e dever, todos se integram ${ }^{3}$. Assim, não questiona a estrutura social, apenas oferece variaçóes de como os indivíduos podem ingressar no modelo hegemonicamente construído pelo gradual processo histórico: "Esse pileque homérico do mundo", em que somos tragados pelo torpor da produtividade, deixando-nos conformar.

Com a instituição do Decreto 5.154/04 (BRASIL, 2004), que revoga o Decreto 2.208/97 (BRASIL, 1997), coloca-se novamente a possibilidade, já explicitada na LDB/96, de rearticular o Ensino Médio com a formação para o trabalho. Nesse decreto, busca-se integrar os conteúdos da formação geral com os da específica.

O documento Educação Profissional do Paraná: Fundamentos políticos e pedagógicos (PARANÁ, 2005), publicado em 2005, que apresenta as principais diretrizes da proposta, anuncia apoiar-se no pressuposto do trabalho como princípio educativo. Retomando Gramsci (2004), para quem não existiria a possibilidade de dissociação entre o trabalho manual e o intelectual, a proposta recupera o conceito de politecnia, que pressupóe a adoção, como princípio metodológico, da "[...] articulação entre teoria e prática, na perspectiva da práxis” (PARANÁ, 2005, p. 18). Assim, destaca: 
O compromisso com uma educação profissional adequada aos interesses dos que vivem do trabalho, ao tomar como princípio educativo o trabalho, implica em desenvolver um percurso educativo em que estejam presentes e articuladas as duas dimensōes, a teórica e a prática, em todos os momentos da formaçáo, contemplando ao mesmo tempo uma sólida formaçáo científica e a formação tecnológica de ponta, ambas sustentadas em um consistente domínio das linguagens e dos conhecimentos sócio-históricos. (PARANÂ, 2005, p. 17).

Na busca de superar a herança educacional do modelo taylorista/fordista de organização da produçáo, o documento destaca que a responsabilidade da educação não se limita em reproduzir abstraçóes desconectadas de seu contexto histórico. Mas deveria levar o aluno a compreender o processo de trabalho em suas dimensões científica, tecnológica e social, ou seja, unificar cultura e trabalho. Baseado em Küenzer, afirma que a finalidade da escola é "[...] a formação de homens desenvolvidos multilateralmente, que articulem à sua capacidade produtiva as capacidades de pensar, de estudar, de dirigir ou de controlar quem dirige" (PARANÁ, 2005, p. 16).

A discussão filosófica do documento fundamentou-se em teóricos da corrente marxista que se opóem aos princípios da educação liberal. Nesse sentido, ao discorrer sobre o currículo integrado, pretende recuperar a relação entre estrutura social e conhecimento. Dessa forma, a concepção de educação integral relaciona-se a uma determinada concepção de homem e de sociedade, com vistas à superação da sociedade dividida em classes. Assim, afirma ser possível organizar um sistema de ensino comprometido com a superação da sociedade capitalista.

Sem adentrar uma detalhada discussão sobre as categorias enunciadas no interior do documento, destacamos que ele avança na análise do currículo escolar, mostrando a vinculação deste com o mercado de trabalho capitalista e aponta a possibilidade de construir uma educaçáo comprometida com os interesses da classe trabalhadora. Nessa linha, defende uma formaçáo que garanta a relação entre ciência, produção e relações sociais, de modo que todos tenham acesso ao conhecimento científico-tecnológico, na perspectiva crítica e transformadora da sociedade. 
Entretanto, inobstante as intenções da equipe encarregada de sua implementação, verificaram-se alguns problemas à medida que tal política foi sendo posta em prática, entre os quais citamos alguns $s^{4}$, referentes ao primeiro ano de funcionamento do PROEJA, em Cascavel.

$\mathrm{O}$ primeiro aspecto de que trataremos diz respeito às atividades planejadas pela equipe pedagógica, professores e gestores para receber os alunos da Educação Profissional e do PROEJA em 2008. O acompanhamento dessas atividades revelou que as açóes planejadas eram de ordem prática e imediata, relacionadas aos aspectos administrativos da escola, tais como a documentaçấo de alunos, a atribuição de aulas, a organização do horário das aulas e do espaço físico, entre outras açóes. Sem dúvida, o planejamento administrativo é essencial para a organização da escola, entretanto, esse planejamento necessariamente deveria se subordinar ao seu objeto - a implementação do currículo integrado, o que não ocorreu.

A proposta do PROEJA, bem como a do currículo integrado deveriam constituir o norte das preocupaçôes daqueles que são responsáveis pela organização e gestão da escola, deveria constituir o eixo orientador de suas decisōes. Por outro lado, os alunos do PROEJA estavam iniciando um curso que continha uma proposição curricular diferenciada do até então vivenciado pela escola e por eles, e a própria recepção desses alunos deveria refletir esse caráter diferenciado. Os dados demonstraram que a equipe pedagógica, os professores e gestores estavam simultaneamente implementando e se apropriando do Programa e da proposta de Currículo Integrado. Daí, a provável dificuldade em planejar açóes com os discentes.

Outro aspecto se refere à organização dos conteúdos a serem ministrados nos cursos profissionais, entre eles, no PROEJA. Os dados demonstraram que as escolas intencionavam organizar os conteúdos em consonância aos princípios defendidos nos Documentos Orientadores elaborados pela SEED/ PR. Entretanto, os profissionais não detinham suficiente clareza de como deveriam e poderiam cumprir tal intento, principalmente no concernente ao trabalho como princípio educativo. Com efeito, trata-se de um pressuposto que se opóe e, portanto, rompe com os pressupostos meramente formais de seleção, organizaçáo e abordagem de conteúdos próprios da escola dualista.

Outra questão que se revelou problemática diz respeito ao conhecimento do Projeto do Curso pelos professores envolvidos. Ficou evidente o desconhecimento dos professores não somente com relaçáo ao Projeto do 
Curso ministrado, como também o da escola em que trabalhavam. Esse desconhecimento foi justificado pelos professores pelas dificuldades de maior participação, uma vez que também atuavam em outras escolas e/ou que desempenhavam outras atividades durante o dia, o que, de certa forma, os impedia de se dedicarem à escola ou ao curso.

Foi também apreendido, a partir dos dados, o problema do não-domínio, pelos professores, da orientação metodológica. Com efeito, um aspecto mencionado pelos professores nas questóes propostas na pesquisa refere-se à dificuldade que encontraram em atuar pedagogicamente nos marcos do método dialético. Os professores percebem a possibilidade de visualizar a integraçáo entre as disciplinas, principalmente por meio do trabalho interdisciplinar, contudo, afirmam que a integração curricular exige conhecimento para além da disciplina que lecionam, demanda tempo e estudo para que a integraçáo seja efetivada na dimensão necessária, ou seja, para que a integração entre as diferentes áreas e disciplinas realmente aconteça. Entendem que há conteúdos cujas especificidades precisam ser preservadas para que não ocorra uma desenfreada procura de articular tudo com tudo, de maneira meramente formal. É evidente, porém, que uma sólida formação necessita de consistente domínio em várias áreas do conhecimento.

Outro aspecto apontado pelos professores e que interfere na possibilidade de colocar em prática o currículo integrado se refere à contratação dos professores da formação específica, pois estes, principalmente no caso dos cursos subsequentes e PROEJA, geralmente são contratados para ministrar a disciplina no semestre. Os apontamentos dos professores revelam que o enfrentamento por uma educação profissional pública que garanta o conhecimento historicamente sistematizado passa não somente pela organização didático-pedagógica dos cursos, mas também por políticas de financiamento e investimento na qualificação e condições de trabalho dos professores.

Se há uma positividade quanto ao acesso dos professores aos cursos de formaçáo continuada ofertados pelo Núcleo Regional de Educaçáo/Cascavel e Secretaria de Educação do Estado do Paraná, bem como à formação de grupos de estudos, não há tempo para discussóes coletivas nas escolas. Os professores não têm a mesma carga horária na instituição, assim, as discussóes e/ou decisões ficam restritas ao atendimento de questôes emergenciais, pontuais. Os professores, dentro do possível, buscam alternativas para trocas de experiências, 
porém, não é possível implementar uma proposta pedagógica contando com a casualidade e "boa vontade" dos envolvidos no processo. "Como é difícil, Pai, abrir a porta" (BUARQUE; GIL, 1973).

Os dados coletados apenas reforçam os inúmeros problemas que a educação brasileira enfrenta, demonstrando que a

[...] proposiçáo de formaçáo humana que tenha como horizonte a emancipação política e econômica dos homens é incompatível com uma estrutura organizada a partir da racionalidade e da lógica da base produtiva capitalista, notadamente de sua expressão técnicoburocrática que é a gestão do trabalho. (VIRIATO; CÊA, 2008, p. 127).

A afirmação, bem como os dados obtidos durante o Curso de Extensão mencionado, nos levaria a pensar que a proposta do currículo integrado estaria fadada ao fracasso, uma vez que é impossível integrar o que, na base, se encontra fragmentado. Poderíamos dizer que "Melhor seria ser filho da outra. Outra realidade menos morta" (BUARQUE; GIL, 1973).

Entretanto, como não somos adeptos do determinismo e do fim da possibilidade histórica, vemos que, na escola, no conhecimento e nos aspectos que envolvem o seu ensino e aprendizagem estâo também presentes as tensôes e contradiçôes da lógica capitalista. Em decorrência, não se deve ignorar o debate em torno do currículo escolar e, por conseguinte, a análise de como este pode contribuir ou não para a superação da dualidade educacional. $\mathrm{O}$ acúmulo dos estudos teóricos educacionais nos fornece dados para compreender a estrutura social e como o currículo tem servido à manutençáo do status quo.

\section{Fundamentos históricos}

Para compreender as possibilidades e os limites impostos ao currículo escolar, se faz necessário percorrermos sua construção histórica, que se compóe em um movimento contraditório de integração e desintegração entre indivíduo, educação escolar e sociedade.

Nesse aspecto, é interessante notar que a escola pública surgiu em conjunto com a estruturação da sociedade capitalista moderna, ou seja, em meados do século XIX, na Europa. Nesse contexto, as relaçóes pautadas nas 
normas religiosas e no isolamento feudal são, paulatinamente, substituídas pela lógica do mercado. $\mathrm{O}$ trabalho passa a ser cada vez mais dividido em uma sociedade dividida. A Revolução Industrial subordina, praticamente, todos os trabalhadores à lógica da produçáo capitalista, e neste processo os trabalhadores, expropriados dos meios de produção, não encontram outra forma de sobrevivência se não a venda de sua força de trabalho ao capital.

Ao ser inserido de forma sistemática na divisão do trabalho e na organização combinada e unificada dos instrumentos de trabalho, o trabalhador teve suas habilidades substituídas pela eficiência da máquina e se tornou simples acessório do processo produtivo. Essa substituição resultou, em primeira mão, na dispensa de força de trabalho e no rebaixamento salarial. Porém, os efeitos da excessiva simplificação do trabalho não pararam aí, afetaram também a mente do trabalhador.

Sobre esta questão, Marx adverte que

[...] não só o trabalho é dividido e suas diferentes fraçóes distribuídas entre os indivíduos, mas o próprio indivíduo é mutilado e transformado no aparelho automático de um trabalho parcial. No sistema industrial capitalista, com a decomposição do processo de trabalho, a habilidade do trabalhador não é necessária. Ela concentra-se no capital que se confronta com o trabalhador.5 (MARX, 1994, p. 413).

Continuando, Marx (1994) afirma ainda que, quando o trabalhador vende sua força de trabalho para outro, perde também uma parte substancial de sua autonomia no processo produtivo, ficando sua atividade reduzida à necessidade de mera reprodução física. $O$ processo do trabalho e a organização da produção são pensados pelo capitalista. O trabalhador fica alheio à totalidade da produção e, identificando-se apenas com o valor de sua força de trabalho (salário), não se reconhece no produto final. Assim, relaciona-se por meio da troca de mercadorias, perdendo a condição de viver relacionamentos pessoais e familiares imediatos, ou seja, que dispensariam a mediação da mercadoria. Nas relaçóes capitalistas, o trabalhador é uma mercadoria que se troca por outras mercadorias; torna-se um alienado em um processo alienante ${ }^{6}$. 
Para Marx (2003), a produção capitalista coisifica as relações humanas, transformando tudo em valor de troca. O trabalho só é trabalho quando se transforma em objeto que tem valor de troca. Assim, complementa que, no processo de troca capitalista:

A alienaçâo do trabalhador no seu produto significa não só que seu trabalho se transforma em objeto, assume uma existência externa, mas que existe independente, fora dele e a ele estranho, e se torna um poder autônomo em oposição a ele; que a vida que deu ao objeto se torna uma força hostil e antagônica. (MARX, 2003, p. 112, grifos no original).

Do exposto acima, podemos afirmar que o sistema capitalista se realiza por contradiçóes e, neste sentido, assim como o capitalismo expropria o trabalhador dos meios de subsistência e do saber, ele também cria a necessidade de formar o homem como um indivíduo que se integra ao sistema produtivo e ao consumo. Com efeito, Marx (1994, p. 556) afirma que, "[...] enquanto o artesanato e a manufatura" subordinam o "[...] produtor a um ramo de produção exclusivo" em que cada ramo da "[...] produçáo encontra, por meios empíricos, a forma técnica conveniente, aperfeiçoa-a lentamente e cristaliza-a", a "[...] indústria moderna" retirou o homem de seu ramo de produção exclusivo:

Criou a moderna ciência da tecnologia o princípio de considerar em si mesmo cada processo de produção e de decompô-lo, sem levar em consideração qualquer intervenção da mão humana, em seus elementos constitutivos. As formas multifárias, aparentemente desconexas e petrificadas do processo social de produçáo se decompóem em aplicaçóes da ciência conscientemente planejadas e sistematicamente especializadas segundo efeito útil requerido. (MARX, 1994, p. 557).

Marx destaca ainda que, neste processo, a indústria moderna "[...] revoluciona constantemente a divisão do trabalho dentro da sociedade e lança ininterruptamente massas de capital e massas de trabalhadores de um ramo de produção para outro", o que exige incessante "[...] variação do trabalho", "[...] fluidez das funçóes, mobilidade do trabalhador em todos os sentidos". (MARX, 1994, p. 558). 
$\mathrm{Na}$ constante modificação dos processos de trabalho, os trabalhadores e consumidores devem estar aptos para executar diferentes tarefas. Nesse caso, a degeneração mental e econômica da massa trabalhadora não pode exceder a necessidade de se manter um exército de reserva de trabalhadores aptos a assumirem as novas funções de trabalho. Segundo Marx:

Torna-se questão de vida ou morte substituir a monstruosidade de uma população operária miserável, disponível, mantida em reserva para as necessidades flutuantes da exploração capitalista, pela disponibilidade absoluta do ser humano para as necessidades variáveis do trabalho; substituir o indivíduo parcial, mero fragmento humano que repete sempre uma operação parcial, pelo indivíduo integralmente desenvolvido para o qual as diferentes funções sociais não passariam de formas diferentes e sucessivas de sua atividade. (MARX, 1994, p. 558-559).

Exposto este limite da expropriaçáo capitalista, Marx (1994, p. 562) esclarece que surge a necessidade social de pôr "[...] barreiras iguais para todos os que exploram o trabalho" e lembra que o Estado necessitou tomar medidas contra os desmandos da exploração capitalista, principalmente no que se refere à necessidade de proteger as crianças da exploraçáo capitalista e da degradação imposta pela divisão do trabalho, como é caso das Leis fabris, entre as quais, uma delas exigia que os empregadores oferecessem ensino escolar aos seus pequenos trabalhadores. Conforme lembra Klein,

[...] a legislação fabril, nos idos do século XIX, apresenta-se por um lado como uma resposta à luta dos trabalhadores e, por outro, como uma resposta do Estado e de setores fabris ao risco a que o próprio capital se expunha com a ruptura dos limites de exploração da mão de obra por alguns capitalistas (KLEIN, 2009, p. 59).

Noutras palavras, significa que expropriação capitalista tem limite. Ou seja, a porca não pode ficar muito gorda, e a faca, mesmo que usada, deve cortar.

Porém, a exigência de escolas infantis repassadas ao empregador significou um encarecimento da força de trabalho infantil: 
As leis fabris impóem limitaçóes à exploração do trabalho infantil e juvenil e também acarretam despesas extras ao patronato, em decorrência das exigências de financiamento de escolarização daquele segmento de trabalhadores, o que torna tal força de trabalho mais onerosa. Nessa circunstância, é natural uma progressiva substituição do contingente de crianças e jovens por trabalhadores adultos - homens e mulheres. (KLEIN, 2009, p. 76).

Como os empregadores não desejavam dispensar frações de mais-valia com a educação, aqueles que não se dispuseram a burlar a lei $^{7}$ dispensaram os pequenos trabalhadores, deixando-os à mercê da educação da rua e, portanto, sujeitos ao ócio e à corrupção. "Tanta mentira, tanta força bruta." No entanto, apesar de sua "aparência mesquinha", Marx escreve que a relativa obrigatoriedade da instrução primária possibilitou "[...] conjugar educação e ginástica com o trabalho manual, e conseqüentemente o trabalho manual com educação e ginástica”, demonstrando-se um "sucesso" (MARX, 1994, p. 553).

No limite de sua época, Marx, reconhece que as escolas politécnicas, agronômicas e de ensino profissional representavam um avanço, quando comparadas ao ensino praticado no artesanato e na produção manufatureira local. Para ele, a educação politécnica, que se apresentava como uma questão de "vida ou morte" para o capital, era também uma tendência, que começava a amadurecer, de se articular ensino e trabalho:

[...] substituir o indivíduo parcial, mero fragmento humano que repete sempre uma operação parcial, pelo indivíduo integralmente desenvolvido para o qual as diferentes funções sociais não passariam de formas diferentes e sucessivas de sua atividade. As escolas politécnicas e agronômicas são fatores desse processo de transformação, que se desenvolveram espontaneamente na base da indústria moderna; constituem também fatores dessa metamorfose as escolas de ensino profissional onde os filhos dos operários recebem algum ensino tecnológico e são iniciados no manejo prático dos diferentes instrumentos de produção. (MARX, 1994, p. 558-559). 
Em razão dessa aproximação entre escola e trabalho, Marx concluiu: não há "[...] dúvida de que a conquista inevitável do poder político pela classe trabalhadora trará a adoção do ensino tecnológico, teórico e prático, nas escolas dos trabalhadores" (MARX, 1994, p. 559).

Com base nas considerações acima, podemos afirmar que a educação pública se tornou uma possibilidade e, ao mesmo tempo, uma necessidade no século XIX. Nesse processo, a escola para a classe trabalhadora surge como uma necessidade produtiva que, na constituição de seu conteúdo curricular, defende que a escola necessita qualificar, preparar e disciplinar a mão-de-obra para o trabalho capitalista. Mas também surge como necessidade social.

A Revolução Industrial, que representou um grande progresso material e a possibilidade de libertar o homem dos limites locais e do trabalho pesado, criou uma massa humana que, expropriada dos bens materiais e valores morais, passou a morar nos becos imundos ${ }^{8}$ e estava propensa a se enfurecer facilmente ${ }^{9}$. Neste cenário, a Igreja Católica, que até então justificava e unificava os homens pelo espírito cristáo, perdeu seu espaço de comando político, e os novos cidadáos passaram a ser congregados como indivíduos trabalhadores, eleitores e consumidores. Diante do perigo, a escola capitalista ampliou seu currículo: juntamente com o ensino da ciência útil, insere-se um conteúdo de cunho moral.

A sociedade que desintegra o trabalho e os homens, no seu oposto, para manter-se, necessita integrá-los no sistema produtivo. Dessa forma, a escola pública, de um lado, traz a divisão e simplificação do ensino, que se traduz na reprodução de um conteúdo escolar simplificado e dividido em pequenos tópicos e em um método baseado na tautologia de abstraçóes que, na tentativa de tornar o aluno mais interessado, reduziu o ensino a um "malabarismo pedagógico" 10 . Do outro lado, a escola é vista como um órgão social que pode contribuir para a unificação das classes. Neste caso, coloca-se a necessidade de formar cidadáos. "Essa palavra presa na garganta/esse pileque homérico no mundo/de que adianta ter boa vontade?" (BUARQUE; GIL, 1973).

Entretanto, se o processo de constituição da sociedade capitalista aliena, sabemos também que a luta entre as classes, explicitada ou não, é fundamento do desenvolvimento capitalista. Neste sentido, na análise educacional, se faz necessário atingir a totalidade. No caso, se a ideologia burguesa encontrase arraigada na forma de os indivíduos agirem, por outro, parece evidente que ela mostra limites. Desta forma, obriga-se a chamar para si termos que 
anteriormente eram utilizados pela crítica capitalista, tais como interesse coletivo, participação política, sujeito crítico.

Nesse processo, destacamos que a luta política não se esgotou com o fim da ditadura - que, ao tentar calar Chico e Gil, permitiu-lhes, contraditoriamente, levantar a voz para além do silêncio imposto -, ela continua a ser uma exigência que, na atualidade, se fortalece no debate educacional. "Talvez o mundo não seja pequeno (Cale-se!)/nem seja a vida um fato consumado (Cale-se!)/quero inventar o meu próprio pecado (Cale-se!)/quero morrer do meu próprio veneno (Pai! Cale-se!)." (BUARQUE; GIL, 1973).

\section{Currículo integrado}

$\mathrm{Na}$ introdução do nosso artigo, ao falar do resgate da possibilidade de emancipação, pensávamos em uma forma de enfrentar o "silêncio", "uma maneira de ser escutado". Não com palavras de ordem, mas pensávamos o currículo integrado como teoria e ação a partir do método e da metodologia dialéticos. Segundo Klein,

[...] no ensino, determinado objeto de conhecimento deverá ser abordado na sua totalidade, o que implica sua não fragmentação, bem como a não disposição etapista dos conteúdos que lhe dizem respeito. Abordar um conteúdo em uma perspectiva de totalidade significa desenvolvê-lo a partir de seus fundamentos, explicitando as relaçóes e mecanismos que articulam seus elementos particulares. Não se trata, pois, de "ir da parte ao todo", nem tampouco de "ir do todo à parte", mas de explicitar, no todo, como é que as partes se articulam de modo a constituir aquela totalidade e não outra (KLEIN, 2007, p. 16).

Mas como pensar em currículo integrado nesta perspectiva em uma sociedade em que reinam a divisão técnica do trabalho e seu corolário, a alienação? Lança luzes sobre essa questão a concepção de escola politécnica referida por Marx (1994) em O Capital, que, apesar de destacá-la como fruto das contradiçôes capitalistas, aponta que ela é portadora da possibilidade de associar ensino e trabalho. Para Marx (1994), essa educação seria o germe da educação do futuro, que conjugará o trabalho produtivo de todos os meninos 
além de uma certa idade com o ensino e a ginástica, constituindo-se em método de elevar a produção social e de único meio de produzir seres humanos plenamente desenvolvidos (MARX, 1994, p. 554).

Nesse caso, a educação escolar deveria se pautar nos avanços da sociedade moderna. Ou seja, na possibilidade de estabelecer uma relação entre trabalho e reflexão teórica. Assim, o ensino deveria combinar diversos elementos da vida humana: trabalho, corpo e mente, sendo esta última entendida como formação geral combinada com a instrução politécnica. Da mesma forma, na Crítica ao Programa de Gotha, Marx afirma que "[...] a combinação do trabalho produtivo com o ensino, desde uma tenra idade, é um dos mais poderosos meios de transformação da sociedade atual" (MARX, s/d, p. 224). Porém, não se referia aqui ao trabalho simples limitado às operaçóes parciais e de tarefas dentro da fábrica, ao contrário, pautava-se no trabalho em sua totalidade.

Assim, uma formação integral significa o resgate da unidade do processo de trabalho, da unidade entre funções manuais e intelectuais, direção e controle do processo de trabalho, a qual só se realiza sob determinada perspectiva metodológica. É preciso sublinhar que mesmo o currículo integrado exige a organização e a seleção formal de determinados conhecimentos científicos (conteúdos escolares), em forma de disciplinas, módulos, projetos, áreas, temas, entre outros. Daí a importância da prática pedagógica do docente, pois o currículo, como teoria, possibilita uma maior ou menor aproximaçáo do conhecimento científico com a prática social, entretanto, as devidas relaçóes são realizadas durante o processo de ensino (ação curricular). É o professor, no desempenho do seu trabalho, que leva o aluno a construir no pensamento a unidade do conteúdo a ser aprendido, que realiza as mediaçóes necessárias entre o conteúdo e a prática/realidade social. Ao fazê-lo, tanto o professor quanto o aluno precisam chegar à essência - historicamente determinada - do conteúdo, buscando a sua unidade, buscando a unidade do currículo, a unidade entre conhecimento sistematizado e tácito. "Mesmo calado o peito resta a cuca/dos bêbados do centro da cidade.” (BUARQUE; GIL, 1973).

Em conformidade Gadotti,

No trabalho pedagógico, o método de exposição deve restabelecer as relaçóes dinâmicas e dialéticas entre os conceitos, reconstituindo as relaçóes que configuram a totalidade concreta da qual se originaram, de modo que 
o objeto a ser conhecido revele-se gradativamente em suas peculiaridades próprias. (GADOTTI, 1995 apud RAMOS, 2009, p. 11).

A integração do currículo, nessa direção, ocorre no método, durante o trabalho do professor, tomando como princípio educativo a categoria "trabalho". A integração dos conteúdos escolares, dispostos em disciplinas, módulos, matérias, áreas, entre outras formas de organização, possibilita assim não somente o domínio do conhecimento historicamente produzido pela humanidade, mas também a compreensão crítica de como este conhecimento é organizado, sistematizado e reproduzido.

Nos dizeres de Ramos,

O trabalho é o princípio educativo no sentido ontológico, pelo qual ele é compreendido como práxis humana e a forma pela qual o homem produz sua própria existência na relação com a natureza e com os outros homens. Sob o princípio do trabalho, o processo formativo proporciona compreensão da historicidade da produção científica e tecnológica, como conhecimentos desenvolvidos e apropriados socialmente para a transformação das condiçóes naturais da vida e a ampliação das capacidades, das potencialidades e dos sentidos humanos. (RAMOS, 2009, p. 5).

Isto significa que o docente, para o adequado exercício da sua prática pedagógica, precisa compreender, minimamente, o princípio metodológico marxista que fundamenta a teoria científica do conhecimento, qual seja, a dialética materialista como método de produção do conhecimento.

\section{Considerações}

Buscamos, no decorrer de nossa exposição, tratar do conhecimento no currículo integrado sob o aspecto da correlação de forças sociais presentes na política educacional. Tomamos como referência o PROEJA, pois este traz, a rigor, a possibilidade de implementar o currículo integrado. Entretanto, como pensar em currículo integrado em uma sociedade em que imperam a divisão técnica do trabalho e a alienação? Mostramos, para exemplificar, alguns aspectos 
vivenciados pelos docentes durante a implantação do PROEJA que ratificam a fragmentação societal.

Tomamos a concepção marxiana de trabalho e educação para mostrar que a educação está integrada ao movimento contraditório da sociedade capitalista. Nesta direção, o que buscamos demonstrar, conforme Marx (1978, p. 224), é que, "[...] por um lado, é preciso uma mudança das condiçóes para criar um sistema de instrução novo; por outro lado, é preciso um sistema de instrução já novo para poder mudar as condiçôes sociais. Por conseguinte, é preciso partir da situação atual".

Vale dizer, o movimento transformador da sociedade não se fixa na escola, mas se faz na luta ao nível das relaçôes sociais de produção. Marx e Engels (s/d) concebe a luta de classes como uma ação intencional, mas esta só adquire força ativa se relacionar-se com a contradição inerente às forças produtivas, nas quais, para Marx, reside o processo de transformaçấo. Dessa forma, pensar o currículo numa perspectiva integrada significa entendê-lo na dinâmica social, nunca como um elemento autônomo, mas historicamente situado na luta de classes e nas condiçóes materiais criadas pela sociedade capitalista.

Nesta perspectiva, o conhecimento escolar "[...] é visto à luz das relaçóes sociais, que ao incorporar o movimento e a contradiçãa, abrem a possibilidade de compreender o desenvolvimento do conhecimento como produto do trabalho social" (FAVORETO; KLEIN, 2012, p. 18). Assim, não se trata de uma luta que se efetiva no imediato, mas, como processo, se constitui na prática de reprodução da vida, tendo a teoria como produto da prática e também como elemento direcionador da luta política e de uma intervençáo consciente na realidade.

Pensar o conhecimento na proposta de currículo integrado significa, desta forma, almejar o desenvolvimento das potencialidades universais do ser humano. É necessário pensar o ensino em sua totalidade, que se compóe de múltiplas determinaçóes construídas na e pela luta diária da vida humana, prenhe de contradiçôes. "Quero perder de vez tua cabeça! (Cale-se!)/minha cabeça perder teu juízo (Cale-se!)/quero cheirar fumaça de óleo diesel (Cale-se!)/me embriagar até que alguém me esqueça (Cale-se!).” (BUARQUE; GIL, 1973).

Em suma, enfrenta-se, então, a necessidade de se postular um currículo que esteja integrado ao método, o qual, por sua vez, expresse a luta de classes em perspectiva de totalidade, ou seja, que possibilite trabalhar os elementos integradores da vida humana em seu movimento histórico e contraditório. "Que é uma maneira de ser escutado." 


\section{Notas}

1 O conceito de inteligência do pensamento escolanovista liberal significa desenvolver a observação e a descoberta, em que pensamento e açáo interligados possibilitem solucionar os problemas da vida prática. Conforme Anísio Teixeira: "Pensar não era contemplar, mas investigar, e investigar nada mais é que trabalhar com a atenção necessária para descobrir o que se passa no trabalho reconstruído e progressivo de todos os que sem capacidade de descobrir, tenham a capacidade de compreender, pelos resultados, o alcance da descoberta, na prática aplicando-a, por ela orientando-se com ela elevando o seu pragmatismo" (TEIXEIRA, 1976, p. 70. apud FAVORETO, 1998, p. 116).

2 Termo utilizado por Harvey (2002) para definir a reestruturação econômica e produtiva implementadas nas últimas décadas do século XX.

3 Sobre a suposta superioridade da racionalidade democrática, podemos citar os seguintes slogans: "Não pergunte o que seu país pode fazer por você, mas sim o que você pode fazer pelo seu país! (John F. Kennedy). "Eu posso" (Barack Hussein Obama).

4 Os dados que permitiram apreender esses problemas foram coletados durante o curso de extensão que os professores Edaguimar Orquizas Viriato, Georgia Sobreira dos Santos Cêa e Roberto Antonio Deitos ofertaram para os docentes vinculados ao PROEJA, em Cascavel. A intenção era verificar a forma como as escolas se organizaram para receber os alunos dos cursos do PROEJA. Os dados foram sistematizados pelas professoras Renata Cristina da Costa Gotardo e Karina Hotz, na ocasião, mestrandas do Programa de Pós-Graduação da Universidade Estadual do Oeste do Paraná/Cascavel.

5 Marx destaca que, no processo de produção capitalista, a "[...] obliteração intelectual dos adolescentes, artificialmente produzida com a transformaçâo deles em simples máquinas de fabricar mais-valia, é bem diversa daquela ignorância natural em que o espírito, embora sem cultura, não perde sua capacidade de desenvolvimento, sua fertilidade natura. Essa obliteração forçou finalmente o Parlamento inglês a fazer da instrução elementar condição compulsória para o emprego 'produtivo' de menores de 14 anos em todas as indústrias sujeitas às leis fabris” (MARX, 1994, p. 456).

6 Ver: Marx, Manuscritos econômico-filosóficos (2003). 
7 Segundo Marx, na escola obrigatória que surgiu com a Revolução Industrial, o "[...] espírito da produção capitalista resplandecia vitorioso na redação confusa das chamadas cláusulas de educação das leis fabris, na falta de aparelhagem administrativa, que tornava freqüentemente ilusória a obrigatoriedade do ensino, na oposição dos próprios fabricantes contra essa obrigatoriedade e nas suas manhas e trapaças para se furtarem a ela" (MARX, 1994, p. 456-457). Assim, era comum aumentar a idade das crianças ou escondê-las no momento da visita do fiscal à fábrica. Os empregadores também trapaceavam oferecendo escolas fantasiosas, com professores analfabetos ou simples atestados de frequência escolar, sem nenhum ensino.

8 Alguns romancistas do século XIX descrevem, nas grandes e barulhentas cidades europeias, uma multidão de transeuntes, cujas vestimentas, formas de andar e aparência física desvendavam sua profissão e posição social. Ou seja, uma multidáo de pessoas, politicamente tratadas como iguais, mas visivelmente diferentes.

9 Émile Zola (1996), em 1885, em sua obra Germinal, destaca que os miseráveis gostavam de falar da "injustiça eterna" e dos "ricos que sugam o sangue dos pobres". Por intermédio de Estevão, personagem da obra, o autor descreve o ódio dos operários mineiros durante a greve, a violência, a promiscuidade reinante nos bairros operários e a destruição dos corpos operários no trabalho (ZOLA, 1996, p. 213).

10 Sobre o malabarismo pedagógico, Otaviano Pereira (1982) comenta que os jovens estão inseridos em uma "política do prazer", a qual pressupóe que tudo o que exige sacrifício é antidemocrático e antiprodutivo, que tem endossado um "[...] processo didático-pedagógico em que professores exercem a função de 'camelos do ensino' ou então meros repetidores de apostilas com respostas prontas, bem buriladas. Aí esses 'bailarinos' de sala de aula (sobretudo professores de cursinhos) pintam como os grandes renovadores à medida que são bem-sucedidos em seu 'strip-tease' didático. Mas quando você assiste a uma segunda ou terceira aula do mesmo professor em classes diferentes, sente que a criaçáo em seu processo reside apenas na mudança de platéia”. (PEREIRA, 1982, p. 10). 


\section{REFERÊNCIAS}

AZEVEDO, Fernando de et al. Manifesto dos Pioneiros da Escola Nova. Revista HISTEDBR On-line, Campinas, SP, n. especial, p.188-204, ago. 2006.

BRASIL.Decreto ํㅡ 2.208, de 17 de abril de 1997. Regulamenta o $\$ 2$ o do art. 36 e os arts. 39 a 42 da Lei no 9.394, de 20 de dezembro de 1996, que estabelece as diretrizes e bases da educação nacional. Diário Oficial da União. Brasília, DF, 18 abr. 1997.

BRASIL. Decreto no 5.154, de 23 de julho de 2004. Regulamenta o $\$$ $2^{\circ}$ do art. 36 e os arts. 39 a 41 da Lei no 9.394, de 20 de dezembro de 1996, que estabelece as diretrizes e bases da educação nacional, e dá outras providências. Diário Oficial da Uniäo. Brasília, DF, 26 jul. 2004.

BUARQUE, Chico; GIL, Gilberto. Cálice. São Paulo: Polygram/Philips, 1973.

DEWEY, John. Experiência e educação. São Paulo: Editora Nacional, 1979.

DUARTE, Newton. Pela superação do esfacelamento do currículo realizado pelas pedagogias relativistas. In: COLÓQUIO LUSO-BRASILEIRO

SOBRE QUESTÓES CURRICULARES, 4.2008, Florianópolis. Anais... Florianópolis, UFSC, set. 2008.

DURKHEIM, Émile. Educação e sociologia. São Paulo: Melhoramentos, 1965.

FAVORETO, Aparecida. Uma análise histórica da concepção de progresso no projeto educacional de Anisio Teixeira. 1998, 182 f. Dissertação (Mestrado em Fundamentos da Educação) - Universidade Estadual de Maringá, Maringá, 1998.

FAVORETO, Aparecida; KLEIN, Lígia Regina. Educação escolar e transformação social: harmonia e contradição em debate. In: VIRIATO, Edaguimar Orquizas; SANDRI, Simone; ESTRADA, Adrian Alvarez (Org.) Politica Pública: interface entre Estado e gestâo escolar. Cascavel: Edunioeste, 2012. No prelo.

GRAMSCI, Antonio. Cadernos do cárcere. Rio de Janeiro: Civilização Brasileira, 2004. v. 2. 
GUARÁ; FERNANDINHO. Problema social. Interpretes: Ana Carolina e Seu Jorge. In: ANA CAROLINA; SEU JORGE. Ana \& Jorge: ao vivo. [S.l.]: Sony, 2006. 1 CD.

HARVEY, David. Condição pós-moderna: uma pesquisa sobre as origens da mudança cultural. São Paulo: Loyola, 2002.

KLEIN, Lígia Regina. O embate pelas leis fabris do século XIX e a definição das idades do trabalho: um estudo sobre a constituição das noçôes de infância e adolescência. 2009, 101 f. (Graduação em Direito) - Setor de Ciências Jurídicas, Universidade Federal do Paraná, Curitiba, 2009.

KLEIN, Lígia Regina. Fundamentos para uma proposta pedagógica. Campo Largo, PR: PM/SED, 2007. Disponível: <http://www.pedagogia.seed.pr.gov. br/arquivos>. Acesso em: 2 jan. 2012.

MARX, Karl. O capital. Rio de Janeiro: Bertrand, 1994.

MARX, Karl. Manuscritos econômico-filosóficos. São Paulo: Martin Claret, 2003.

MARX, Karl. Crítica ao programa de Gotha. In: MARX, Karl; ENGELS, Friedrich. Obras escolhidas. São Paulo: Alfa-Omega, s/d. p. 205-234. v. 2.

MARX, Karl; ENGELS, Friedrich. Manifesto do Partido Comunista. In: Karl Marx e Friedrich Engels. Obras Escolhidas. São Paulo: Alfa-Omega, s/d. p. 13-47.v. 1.

MARX, Karl; ENGELS, Friedrich. Exposição de Marx na seção de 10 e 17 de agosto de 1869 no Conselho Geral da AIT. In: DANGEBILLE, Roger. Crítica da educação e do Ensino: introdução e notas. Lisboa/Portugal: Moraes, 1978, p. 224-226.

PAÍS tem pior evasão escolar do Mercosul. $O$ Globo. Rio de janeiro, 18 de set. de 2010.

PAIVA, Vanilda. Produção, qualificação e currículos. Educação e Sociedade, Campinas, SP, n. 37, p. 37-47, dez. 1990.

RAMOS, Marise Nogueira. Currículo Integrado. In: DICIONÁRIO da Educação Profissional em Saúde. Rio de Janeiro: Fundação Oswaldo Cruz, 2009. Disponível em: <http://www.epsjv.fiocruz.br/dicionario/verbetes/ curint.html $>$. Acesso em: 2 jan. 2012. 
PARANÁ. Secretaria de Estado de Educação. Diretrizes Educação Profissional no Paraná: Fundamentos Políticos e Pedagógicos. Curitiba, PR: SEED, 2005.

PEREIRA, Otaviano. O que é Teoria. São Paulo: Brasiliense, 1982.

SAVIANI, Demerval. Escola e democracia. São Paulo: Cortez, 1983.

SILVA, Tomaz Tadeu. Identidades terminais: as transformaçóes na política da pedagogia e na pedagogia da política. Petrópolis: Vozes, 1996.

VIRIATO, Edaguimar Orquizas. Prosear... Apenas uma prosa, nada mais! Revista Travessias, Cascavel, v. 4, n. 2, p. 750-772. 2010.

VIRIATO Edaguimar Orquizas; CÊA, Georgia Sobreira dos Santos.

Implicaçôes da perspectiva gerencial aplicada à organização e à gestão escolar. In: FIGUEIREDO, Ireni Marilene Zago; ZANARDINI, Isaura Monica Souza; DEITOS, Roberto Antonio (Org.). Educação, políticas sociais e Estado no Brasil. Cascavel: Edunioeste, 2008. p. 119-148.

ZOLA, Émile. Germinal. São Paulo: Nova Cultural, 1996. 


\section{Trabajo docente, PROEJA y currículum integrado: algunas reflexiones}

\section{Resumen}

En la multitud de cuestiones que impregnan el debate del plan de estudios, en su vasta complejidad, hemos elegido para tratar la cuestión del conocimiento en el currículo integrado, esta política educativa centrada en la educación profesional, en particular el Programa de Integración de la Educación Profesional en la Escuela de Jóvenes y Adultos (PROEJA). Adoptamos como herramienta metodológica para comprender el estudio de la literatura y el análisis de fuentes primarias (la legislación en materia de educación) y fuentes secundarias (tesis, tesinas, informes de investigación, libros, revistas). Señalamos la necesidad de postular un plan de estudios que se integre en el método, el cual, a su vez, exprese la lucha de clases en perspectiva de la totalidad, es decir, que permita a los integradores para trabajar los elementos de la vida humana en su movimiento histórico y contradictorio.

Palabras clave: Plan de Estudios de Integración. Conocimiento. Formación Profesional Integrada.

\section{The work of teaching, PROEJA and integrated curriculum: some reflections}

\section{Abstract}

From the infinity of issues that pervade the vast and complex debate about school curriculum, we address the question of knowledge in the integrated curriculum, which is found in educational policy aimed at professional education, particularly in the Program to Integrate Professional Education to High School in the Modality for Youth and Adults (PROEJA). We use bibliographic research as a methodological tool, including a survey and analysis of primary sources (educational legislation) and secondary sources (theses, dissertations, research reports, books, and journals). We point to the need to postulate a curriculum that is integrated to method, which, in turn, expresses a total perspective of class struggle, in other words, which allows working with the elements that integrate human life in its historic and contradictory movement.

Keywords: Integration Curriculum. Knowledge. Integrated Professional Education. 
Edaguimar Orquizas Viriato

E-mail: edaguimar@gmail.com

Aparecida Favoreto

E-mail: cidafavoreto@globo.com

Lígia Regina Klein

E-mail: lklein@gmail.com

Recebido em: 11/1/2012

Versáo final recebida em: 5/6/2012 